\title{
Risk Factors Associated with Birth Asphyxia in Rural District Matiari, Pakistan: A Case Control Study
}

\author{
Farhana Tabassum, Arjumand Rizvi, Shabina Ariff, Sajid Soofi, Zulfiqar A. Bhutta \\ Department of Pediatrics and Child Health, Aga Khan University, Karachi, Pakistan \\ Email: farhana.tabassum@aku.edu
}

Received 24 October 2014; revised 23 November 2014; accepted 4 December 2014

Copyright (C) 2014 by authors and Scientific Research Publishing Inc.

This work is licensed under the Creative Commons Attribution International License (CC BY). http://creativecommons.org/licenses/by/4.0/

(c) (i) Open Access

\section{Abstract}

Background: During the past two decades there has been a sustained decline in child mortality; however, neonatal mortality has remained stagnant. Each year approximately 4 million babies are born asphyxiated resulting in 2 million neonatal deaths and intrapartum stillbirths. Almost all neonatal deaths occur in developing countries, where the majority is delivered at homes with negligible antenatal care and poor perinatal services. Objectives: To identify socio-demographic and clinical risk factors associated with birth asphyxia in Matiari District of Sindh Province, Pakistan. Method: A matched case control study was conducted in Matiari District with 246 cases and 492 controls. Newborn deaths with birth asphyxia diagnosed through verbal autopsy accreditation during 2005 and 2006 were taken as cases. Controls were the live births during the same period, matched on area of residence, gender and age. Result: The factors found to be associated with birth asphyxia mortality in Matiari District of Sindh Province, Pakistan are maternal education, history of stillbirths, pregnancy complications (including smelly or excessive vaginal discharge and anemia), intrapartum complications (including fever, prolong or difficult labour, breech delivery, cord around child's neck, premature delivery, large baby size) and failure to establish spontaneous respiration after birth. Conclusion and Recommendation: There is an immediate need to develop strategies for early identification and management of factors associated with birth asphyxia by involving women, families, communities, community health workers, health professionals and policy makers. Community health workers should be trained for emergency obstetric care, basic newborn care including preliminary resuscitation measures to provide skilled birth attendance and encourage early recognition and referral.

\section{Keywords}

Birth Asphyxia, Prolong Labor, Antenatal Care 


\section{Background}

Most developing countries have witnessed substantial declines in under 5 mortality [1] while in contrast, neonatal deaths have remained stagnant with an estimated 3 million annual neonatal deaths occurring globally [2]. Recent estimates showed that annual reduction rate in neonatal mortality between 1990 and 2012 (2\%) was much lower than that for children aged 1 - 59 months (3.4\%) [3] [4]. Birth asphyxia (BA) is one of the leading causes of newborn mortality [5]-[7]. Each year approximately $24 \%$ of neonatal deaths occurred due to birth asphyxia [1] with an equal number of survivors with serious neurological squeals, such as cerebral palsy, mental retardation and epilepsy leading to detrimental long term consequences for both child and family [8]-[12].

Birth asphyxia is defined by the World Health Organization as "the failure to initiate and sustain breathing at birth" [13]. Birth asphyxia occurs when an inadequate amount of oxygen is delivered to the fetus, usually during labor and childbirth, leading to risk of death (stillbirth or neonatal death) or lifelong disability in the surviving infant. Cognitive and behavioral difficulties can also be expected because of the patterns of brain injury that have been associated with neonatal encephalopathy. The hippocampus and striatum are among the brain structures that can be affected [14]-[18]. These structures have been associated with specific cognitive functions such as memory and attention and hypothesized to play a role in the pathogenesis of attention deficit hyperactivity disorder (ADHD), autism and schizophrenia [19]-[23]. Other terms sometimes used for birth asphyxia include perinatal asphyxia and fetal distress. Birth asphyxia can be caused by events that have their roots in the antepartum, intrapartum, postpartum periods or combinations thereof. A recent review suggests that asphyxia is probably primarily antepartum in origin in $50 \%$ of cases, intrapartum in $40 \%$, and postpartum in the remaining $10 \%$ of cases [24]. Definitions of birth asphyxia designed for use in hospital-based settings require evaluation of neonatal umbilical cord $\mathrm{pH}$, Apgar scores, neurological clinical status, and markers of multi-system organ function, which are not feasible in community settings. Therefore, it is difficult to recognize the causes of birth asphyxia in the community due to lack of a consistent definition [25].

In 2013, lower-middle-income countries (LMIC) share 98\% of the total newborn mortality burden [6] whereas more than 4 in 10 of all neonatal deaths worldwide occurred in just three countries: India, Nigeria, and Pakistan [1]. Pakistan ranks 5th in the list of countries bearing the highest neonatal mortality burden globally [1]. Birth asphyxia contributes to around $40 \%$ of the neonatal mortality burden in Pakistan and a major fraction of these deaths occurs in rural areas (74\%) [26]. A majority of these women give birth at home and are either unassisted or assisted by an unskilled birth attendant, including family and traditional birth attendants (TBA). Risk factors of birth asphyxia in community and hospital based settings in developing countries have been categorized into demographic, antepartum, intrapartum and neonatal risk factors presented in (Table 1). The aim of this study was to explore potential risk factors associated with birth asphyxia in resource poor settings in Pakistan. This will help in targeting and scaling up of proven and cost effective interventions for preventing the identified risk factors associated with birth asphyxia in community setting.

To the best of our knowledge this is the first study to identify risk factors of BA mortality among neonates

Table 1. Antepartum, intrapartum, and infant risk factors for birth asphyxia previously reported from hospital based studies.

\begin{tabular}{|c|c|c|c|}
\hline \multirow{2}{*}{$\begin{array}{l}\text { Community based study } \\
\text { Demographic risk factors }\end{array}$} & \multicolumn{3}{|c|}{ Hospital based studies } \\
\hline & Antepartum risk factors & Intrapartum risk factor & Infant/postnatal \\
\hline $\begin{array}{l}\text { Parental education and } \\
\quad \text { occupation [57] }\end{array}$ & Primiparity [45] [58] & Malpresentation [41] [46] [59] & Prematurity [60] \\
\hline \multirow[t]{6}{*}{ Cast and ethnicity [57] } & Maternal fever [41] & Prolonged labor [40] [46] & Low birth weight [41] [47] \\
\hline & $\begin{array}{l}\text { Pregnancy induced } \\
\text { hypertension [45] [46] }\end{array}$ & $\begin{array}{l}\text { Meconium stained amniotic } \\
\text { fluid [40] [41] [45] [59] }\end{array}$ & $\begin{array}{l}\text { Intrauterine growth } \\
\text { restriction [46] [58] }\end{array}$ \\
\hline & Anemia [41] & Pre-eclampsia [41] & \\
\hline & Antepartum hemorrhage [41] [45] & $\begin{array}{l}\text { Premature rupture of } \\
\text { membranes }[41]\end{array}$ & \\
\hline & History of prior neonatal death [45] & $\begin{array}{l}\text { Oxytocin augmentation } \\
\text { of labor }[41]\end{array}$ & \\
\hline & & $\begin{array}{c}\text { Umbilical cord } \\
\text { prolapsed [46] [59] }\end{array}$ & \\
\hline
\end{tabular}


conducted in rural resources limited settings in Pakistan.

\subsection{Material and Methods}

It was a matched case control study conducted from September 2009 to January 2010 in Matiari District of Sindh Province, Pakistan. The estimated population of the area is about 5 million. The Matiari District is administratively divided into taluk as which further comprised of 19 union councils. The study area was selected on the availability of verbal autopsies data on under 5 mortality captured during the survey conducted by department of Paediatrics \& Child Health in year 2005-2006. Neonatal death (0 - 28 days) rate was 50/1000 live births as per the available data. Verbal autopsies of all neonatal deaths captured during the survey were reviewed by trained Pediatricians to assign a reference standard primary cause of death. The verbal autopsy concluded that around $30 \%$ of all neonatal deaths were caused by birth asphyxia. We took these deaths as cases while controls were the live births of same area during the same period, matched on gender and age to reduce confounding by these variables.

Sample size was calculated using the proportion of birth asphyxia among controls (22.1\%) from the Pakistan Demographic and Health Survey PDHS2006-07. Expecting to obtain an odds ratio of 1.5, required sample size was 246 cases over 492 controls, at $5 \%$ level of significance and $80 \%$ power.

The study teams comprised of research assistant from the local community and were trained on data collection instruments and study methodology. A structured data collection tool was designed and administered after informed verbal consent from mother of case or control child. Data was collected on a wide range of factors including household demographics, reproductive history, antenatal care seeking, maternal complication during pregnancy, labor, delivery and neonatal complications at birth. To ensure quality of data collection, project supervisor checked $5 \%$ of the total forms. The fieldwork was very closely monitored by the team leader and prior to data entry, all forms were checked for completeness and consistency as well as coding of open ended responses and area code, etc. In case of inconsistency or missing responses, the field supervisor flagged the errors and consulted the interviewers for possible explanations. All data was entered twice for the purpose of sufficient accuracy. Data quality was assured by performing dual and error checks simultaneously with data entry. A sub sample of data was checked manually for validation.

\subsection{Statistical Analysis}

To evaluate potential predictors for birth asphyxia mortality risk factors were grouped into four major domains: socio-demographics, antepartum, intrapartum, and postnatal or infant characteristics. Univariate distributions were explored using frequencies/proportions, and means/medians and histograms, as appropriate. Multivariate analysis was conducted via conditional logistic regression to ensure adequate statistical power and efficiency. Results are reported as the odds ratios (OR) with respective 95\% CI. All potential covariates were examined independently in univariate analysis. Variables significant at a liberal $\mathrm{p}<0.25$ were considered for adjustment in the multivariate model. Covariates that were found insignificant at multivariate level were dropped consecutively from model after careful assessment of confounding. The final model was selected on the basis of theoretical and statistical significance of predictors. Type 1 error rate was held at 0.05 and statistical analyses were performed using STATA (version 12).

\subsection{Ethical Considerations}

The study protocol was examined and approved by the Aga Khan University ethics review committee.

\section{Results}

\subsection{Socio-Demographic Risk Factors}

We studied 246 cases and 492 controls. Among various socio-demographic indicators birth asphyxia was found to be significantly associated with mother and father education levels. Maternal literacy decreased the risk of mortality with birth asphyxia (OR 0.5, 95\% CI: 0.3 - 0.7) while father's higher education levels possessed protective effect on mortality (OR 0.5, 95\% CI: 0.3 - 0.9). Significant association was not established with major socio-demographic determinants such as socio-economic position (SES quintiles), improved water and sanitation facilities with birth asphyxia (Table 2). 
Table 2. Socio-demographic risk factors of birth asphyxia mortality.

\begin{tabular}{|c|c|c|c|c|}
\hline Exposure & Control $(n=492)$ & Cases $(n=246)$ & OR & p-value \\
\hline \multicolumn{5}{|l|}{ HH characteristics } \\
\hline \multicolumn{5}{|l|}{ Source of drinking water } \\
\hline Tap in house & 73.0 & 69.9 & 1 & \\
\hline Public tap & 9.1 & 11.8 & $1.4(0.8-2.5)$ & 0.26 \\
\hline Other & 17.9 & 18.3 & $0.9(0.5-1.8)$ & 0.92 \\
\hline \multicolumn{5}{|l|}{ Kind of toilet facilities } \\
\hline Latrine with flush system & 37.4 & 35.8 & 1 & \\
\hline Latrine without flush system & 18.9 & 16.7 & $0.9(0.4-1.9)$ & 0.85 \\
\hline No facilities/use the fields & 43.7 & 47.6 & $1.4(0.8-2.4)$ & 0.30 \\
\hline \multicolumn{5}{|l|}{ Wealth quintiles } \\
\hline Poorest & 21.1 & 17.1 & $0.6(0.3-1.2)$ & 0.17 \\
\hline Poorer & 20.3 & 19.9 & $0.8(0.5-1.6)$ & 0.70 \\
\hline Middle & 18.1 & 23.6 & $1.2(0.7-2.2)$ & 0.42 \\
\hline Richer & 20.7 & 19.1 & $0.8(0.5-1.5)$ & 0.65 \\
\hline Richest & 19.7 & 20.3 & 1 & \\
\hline \multicolumn{5}{|l|}{ Respondent characteristics } \\
\hline \multicolumn{5}{|l|}{ Maternal education } \\
\hline No formal schooling & 76.8 & 85.8 & 1 & \\
\hline Literate (primary or above) & 23.2 & 14.2 & $0.5(0.3-0.7)$ & 0.001 \\
\hline \multicolumn{5}{|l|}{ Maternal occupation } \\
\hline Unemployed & 89.2 & 88.6 & 1 & \\
\hline Employed & 10.8 & 11.4 & $1.1(0.6-1.9)$ & 0.77 \\
\hline \multicolumn{5}{|l|}{ Father age } \\
\hline$<40$ years & 78.7 & 77.6 & 1 & \\
\hline$\geq 40$ years & 21.3 & 22.4 & $1.0(0.7-1.5)$ & 0.86 \\
\hline \multicolumn{5}{|l|}{ Father education } \\
\hline No formal schooling & 46.4 & 54.1 & 1 & \\
\hline Primary/middle & 22.6 & 23.6 & $1(0.6-1.5)$ & 0.87 \\
\hline Metric or above & 31.1 & 22.4 & $0.5(0.3-0.9)$ & 0.01 \\
\hline
\end{tabular}

"Wealth quintiles constructed through PCA using construction of HH, no of rooms, cooking fuel, electrification, source of drinking water and sanitation facilities.

\subsection{Antepartum Risk Factors}

Our data shows significant association of birth asphyxia with increasing maternal age (OR: 1.4, 95\% CI: 1.1 2.0), poor dietary intake (OR: 2.2, 95\% CI 1.4 - 3.3), reproductive history including shorter birth intervals (OR: 1.8, 95\% CI: 1.2 - 2.6), prior stillbirths (OR: 2.9, 95\% CI: 1.9 - 4.5) and child deaths (OR: 94, 95\% CI: 30 - 295) and complications during pregnancy including self-reported high blood pressure (OR: 2, 95\% CI: 1.3 - 2.9), bleeding from the vagina (OR: 3.3, 95\% CI: 1.6 - 6.8), smelly or excessive vaginal discharge (OR: 3.1, 95\% CI: 1.8 - 5.2), severe abdominal pain (OR: 1.7, 95\% CI: 1.2 - 2.5), swelling on body (OR: 1.5, 95\% CI: 1.1 - 2.2). However, maternal malnutrition and working routine did not appear to contribute to BA mortality (Table 3 ). 
Table 3. Antepartum risk factors of birth asphyxia mortality.

\begin{tabular}{|c|c|c|c|c|}
\hline Exposure & Control $(n=492)$ & Cases $(n=246)$ & OR & p-value \\
\hline \multicolumn{5}{|l|}{ Maternal age } \\
\hline$<30$ years & 42.3 & 34.6 & 1 & \\
\hline $30+$ years & 57.7 & 65.4 & $1.4(1.1-2.0)$ & 0.03 \\
\hline \multicolumn{5}{|l|}{ Maternal malnutrition } \\
\hline Low BMI $(<18.5)$ & 28.7 & 26.5 & $0.9(0.6-1.3)$ & 0.54 \\
\hline Short stature (ht $<145 \mathrm{~cm}$ ) & 11.8 & 12.2 & $1.0(0.6-1.7)$ & 0.86 \\
\hline \multicolumn{5}{|l|}{ Food habits during pregnancy } \\
\hline More or usual diet & 85.3 & 75.2 & 1 & \\
\hline Less than usual diet & 14.6 & 24.8 & $2.2(1.4-3.3)$ & 0.0003 \\
\hline \multicolumn{5}{|l|}{ Working habits during pregnancy } \\
\hline Less than usual work & 13.8 & 9.7 & 1 & \\
\hline More or usual work & 86.2 & 90.2 & $1.5(0.9-2.5)$ & 0.1 \\
\hline \multicolumn{5}{|l|}{ Birth history } \\
\hline Miscarriages & 20.7 & 25.2 & $1.3(0.9-1.8)$ & 0.15 \\
\hline Still birth & 12.0 & 26.4 & $2.9(1.9-4.5)$ & $<0.001$ \\
\hline Child death & 31.9 & 97.6 & $94.2(30.1-295.3)$ & $<0.001$ \\
\hline Birth interval $<2$ years & 66.3 & 77.4 & $1.8(1.2-2.6)$ & 0.001 \\
\hline \multicolumn{5}{|l|}{ Complications during pregnancy } \\
\hline Bleeding from the vagina & 3.05 & 8.94 & $3.3(1.6-6.8)$ & 0.001 \\
\hline Smelly or excessive vaginal discharge & 7.11 & 17.48 & $3.1(1.8-5.2)$ & $<0.001$ \\
\hline $\begin{array}{l}\text { Severe or persistent abdominal or back pain } \\
\text { that was not labour pain }\end{array}$ & 29.07 & 37.80 & $1.7(1.2-2.5)$ & 0.006 \\
\hline Swelling on body parts (hand, face, leg) & 26.42 & 33.74 & $1.5(1.1-2.2)$ & 0.02 \\
\hline Blurring of vision & 47.15 & 54.07 & $0.4(1-1.9)$ & 0.06 \\
\hline Severe headache & 58.54 & 65.85 & $1.4(1.0-2.0)$ & 0.05 \\
\hline High blood pressure & 30.49 & 41.46 & $2(1.3-2.9)$ & 0.001 \\
\hline Anaemia/pallor & 21.54 & 29.67 & $1.6(1.1-2.4)$ & 0.01 \\
\hline
\end{tabular}

\subsection{Intrapartum Risk Factors}

Almost half of the deliveries took place at medical facilities, proportion of hospital births being higher in cases than in controls (OR 1.6, 95\% CI: 1.1 - 2.4). Complications during labor and delivery including high blood pressure (OR 2.4, 95\% CI: 1.6 - 3.6), convulsions (OR 2.8, 95\% CI: 1.5 - 5.2), excessive bleeding (OR 2.8, 95\% CI: 1.6 - 5.1), water bag broke before labor (OR 2.8, 95\% CI: 1.2 - 6.5), breech delivery (OR 6.2, 95\% CI: 2.8 13.8), prolong labor (OR 5.2, 95\% CI: 3.3 - 8.3) and baby movement stopped (OR 4.9, 95\% CI: 1.7 - 13.9) were significantly associated with increased risk of birth asphyxia mortality. Exact gestational age was not available therefore mother's reported duration of pregnancy was taken as proxy and the data suggests that early ended pregnancies carried higher risk of birth asphyxia mortality (OR 5.4, 95\% CI: 2.9 - 10). Delivery augmented with medicine significantly predict increased chances of birth asphyxia mortality (OR 2.2, 95\% CI: 1.4 - 3.4) (Table 4).

\subsection{Neonatal Risk Factors}

Data on birth weight was not available therefore size at birth taken as proxy. Small size at birth was associated 
Table 4. Intrapartum risk factors of birth asphyxia mortality.

\begin{tabular}{|c|c|c|c|c|}
\hline Exposure & Control $(n=492)$ & Cases $(n=246)$ & OR & p-value \\
\hline \multicolumn{5}{|l|}{ Complications occurred during labour } \\
\hline High blood pressure & 29.30 & 42.30 & $2.4(1.6-3.6)$ & $<0.001$ \\
\hline Convulsions & 4.50 & 11.00 & $2.8(1.5-5.2)$ & 0.001 \\
\hline Fever & 16.10 & 28.50 & $2.4(1.6-3.6)$ & $<0.001$ \\
\hline Excessive bleeding & 5.50 & 12.60 & $2.8(1.6-5.1)$ & 0.001 \\
\hline Prolonged/difficult labour & 13.8 & 37.0 & $5.2(3.3-8.3)$ & $<0.001$ \\
\hline Breech delivery & 1.6 & 10.2 & $6.2(2.8-13.8)$ & $<0.001$ \\
\hline Cord around child's neck & 2.2 & 4.1 & $2(0.8-5)$ & 0.13 \\
\hline \multicolumn{5}{|l|}{ Place of delivery } \\
\hline Home & 42.1 & 33.3 & 1 & \\
\hline Hospital & 57.9 & 66.7 & $1.6(1.1-2.4)$ & 0.009 \\
\hline \multicolumn{5}{|l|}{ Last movement in the womb } \\
\hline During labour or delivery & 98.4 & 93.5 & 1 & \\
\hline At least one or two day prior to delivery & 1.2 & 5.3 & $4.9(1.7-13.9)$ & 0.003 \\
\hline \multicolumn{5}{|l|}{ Pregnancy ends up } \\
\hline Early & 3.7 & 17.9 & $5.4(2.9-10)$ & $<0.001$ \\
\hline In time & 88.0 & 72.8 & 1 & \\
\hline Late & 7.9 & 8.9 & $1.5(0.8-2.7)$ & 0.21 \\
\hline \multicolumn{5}{|l|}{ Labour type } \\
\hline Spontaneous without medication & 62.0 & 51.6 & 1 & \\
\hline Induced with medicine & 9.1 & 12.2 & $1.3(0.7-2.4)$ & 0.42 \\
\hline Augmented with medicine & 28.9 & 36.2 & $2.2(1.4-3.4)$ & 0.001 \\
\hline \multicolumn{5}{|l|}{ Timing of breakage of water bag } \\
\hline Before labour & 4.3 & 8.1 & $2.8(1.2-6.5)$ & 0.014 \\
\hline During labour & 95.6 & 91.8 & 1 & \\
\hline \multicolumn{5}{|l|}{ Length of delivery and labor } \\
\hline Less than 12 hours & 93.1 & 80.9 & 1 & \\
\hline Twelve hours or more & 6.7 & 19.1 & $4.3(2.4-7.5)$ & $<0.001$ \\
\hline \multicolumn{5}{|l|}{ Outcome of delivery } \\
\hline Singleton & 98.8 & 95.9 & 1 & \\
\hline Multiple & 1.2 & 4.1 & $1(0.9-1.1)$ & 0.63 \\
\hline
\end{tabular}

with increased risk of birth asphyxia mortality (OR 2.5, 95\% CI: 1.5 - 4.1) whereas being large at birth had twice more risk of mortality due to birth asphyxia (OR 4.1, 95\% CI: 2.0 - 8.3). Other significantly associated neonatal risk factors were difficult breathing (OR 79, 95\% CI: 29 - 214), baby not breathing immediately after birth (OR 38.4, 95\% CI: 18.9 - 78.1), cyanosis (OR 301, 95\% CI: 42 - 2147) and chest in drawing after birth (OR 2.3, 95\% CI: 1.5 - 3.8) (Table 5).

\subsection{Multivariate Models}

Multivariate analysis yielded interesting results as some of the associations between outcome and predictors 
Table 5. Neonatal risk factors of birth asphyxia mortality.

\begin{tabular}{|c|c|c|c|c|}
\hline Exposure & Control $(n=492)$ & Cases $(n=246)$ & OR & p-value \\
\hline \multicolumn{5}{|l|}{ Size of baby at birth } \\
\hline Smaller than average & 12.2 & 20.3 & $2.5(1.5-4.1)$ & $<0.001$ \\
\hline Average & 84.1 & 67.9 & 1 & \\
\hline Larger than average & 3.5 & 11.8 & $4.1(2.0-8.3)$ & $<0.001$ \\
\hline Failure to develop spontaneous breathing & 6.9 & 70.6 & $38.4(18.9-78.1)$ & $<0.001$ \\
\hline Color of the baby turned blue after 5 minutes of birth & 2.3 & 67.2 & $301(42-2147)$ & $<0.001$ \\
\hline Difficult breathing after birth & 9.8 & 81.6 & $79(29-214)$ & $<0.001$ \\
\hline Chest in drawing after birth & 9.1 & 17.9 & $2.3(1.5-3.8)$ & $<0.001$ \\
\hline Nostrils flare with breathing & 38.2 & 27.4 & $0.4(0.3-0.7)$ & $<0.001$ \\
\hline
\end{tabular}

were not found significant after controlling the effect of other variables although these predictors have shown conspicuous relationship during bi-variate analysis. The significant mortality contributory factors were maternal education (OR: 3.2, 95\% CI: 1.2 - 8.5), history of stillbirths (OR: 4.4, 95\% CI: 1.8 - 10.8), smelly or excessive vaginal discharge (OR: 3.1, 95\% CI: 1.1 - 8.4) or anemia (OR: 2.2, 95\% CI: 1.0 - 4.9) during pregnancy, intrapartum complications such as fever (OR: 2.4, 95\% CI: 1.0 - 5.6), prolong labour (OR: 3.8, 95\% CI: 1.5 - 9.6), breech delivery (OR: 6.1, 95\% CI: 1.2 - 31.8) and cord around child's neck (OR: 8.8, 95\% CI: 1.4 - 54.5), duration of pregnancy (proxy for gestational age) (OR: 5.3, 95\% CI: 1.7 - 16.8), large size of baby at birth (proxy for birth weight) (OR: 5.3, 95\% CI: 1.6 - 16.9) and child didn’t cry immediately after birth (OR: 53.8, 95\% CI: 20.7 - 139.6) (Table 6).

\section{Discussion}

Our study demonstrates that maternal education, history of stillbirths, prenatal complications (including smelly or excessive vaginal discharge and anemia) and intrapartum complications (including fever, prolong or difficult labour, breech delivery, cord around child's neck, premature delivery, large baby size and failure to establish spontaneous respiration after birth) were significantly associated with higher risk of neonatal mortality related to birth asphyxia in Matiari District of Pakistan. To our knowledge, this is the first study to identify risk factors of birth asphyxia mortality among newborns, conducted in rural resource limited settings in Pakistan, where quality of care is inadequate to respond to emergency situations. We evaluated broad range of risk factors including socio-demographic, antenatal, intrapartum and neonatal complications.

Among the sociodemographic risk factors, our study identified maternal education as one of the factors associated with BA mortality. Similar patterns were reported by other studies conducted in rural areas of Southern Nepal and Mexico City [27] [28]. Another hospital based study conducted in Bangladesh did not find association of maternal education with BA [29]. Maternal illiteracy is a very broad indicator of poor socio-economic conditions associated with consequent malnutrition, frequent pregnancies and also influence care seeking during antepartum period. Our data also suggests that history of stillbirths is significantly associated with increased risk of birth asphyxia mortality and this finding is concordance with the findings from studies conducted in similar settings from less developed countries [30]-[33]. We did not find any association between birth asphyxia related mortality and maternal age. This finding is consistent with other studies [29] [34].

It is well known that diseases and complications during pregnancy are the most important risk factors of perinatal mortality [35]-[39]. Among antenatal risk factors, our study showed that antepartum complications (including smelly or excessive vaginal discharge and anemia or pallor) were the most important factors related to increased risk of BA mortality. Previous studies have shown similar results [40] [41]. Among intrapartum risk factors, presence of fever (indicative of infection), prolonged labor, breech delivery and cord around child's neck were found to be associated with high BA mortality. These findings are consistent with other studies [27] [29] [40]-[47]. We did not find any association of BA mortality with convulsions and vaginal bleeding. Other studies conducted in resource limited settings have reported similar results [27]. However, this could be due to self-reported and non-specific nature of data. Among neonatal risk factors, we found preterm birth to be 
Table 6. Multivariate analysis of risk factors of birth asphyxia mortality.

\begin{tabular}{|c|c|c|c|}
\hline Indicators & Adjusted OR & $95 \% \mathrm{CI}$ & p-value \\
\hline \multicolumn{4}{|l|}{ Maternal education } \\
\hline No formal schooling & 3.2 & $1.2-8.5$ & 0.02 \\
\hline Literate (primary or above) & 1 & & \\
\hline Reproductive history of stillbirth & 4.4 & $1.8-10.8$ & $<0.001$ \\
\hline \multicolumn{4}{|l|}{ Prenatal complications } \\
\hline Smelly or excessive vaginal discharge & 3.1 & $1.1-8.4$ & 0.03 \\
\hline Anemia/pallor & 2.2 & $1.0-4.9$ & 0.05 \\
\hline \multicolumn{4}{|l|}{ Intrapartum complications } \\
\hline Fever & 2.4 & $1.0-5.6$ & 0.04 \\
\hline Prolong/difficult labor & 3.8 & $1.5-9.6$ & 0.01 \\
\hline Breech delivery & 6.1 & $1.2-31.8$ & 0.03 \\
\hline Cord around child's neck & 8.8 & $1.4-54.4$ & 0.02 \\
\hline \multicolumn{4}{|l|}{ When this pregnancy end? } \\
\hline Early & 5.3 & $1.7-16.8$ & $<0.001$ \\
\hline In time & 1 & & \\
\hline Late & 1.2 & $0.3-4.1$ & 0.82 \\
\hline \multicolumn{4}{|l|}{ Size of baby at birth? } \\
\hline Smaller than average & 0.4 & $0.1-1.0$ & 0.04 \\
\hline Average & 1 & & \\
\hline Larger than average & 5.3 & $1.6-16.9$ & 0.01 \\
\hline Failure to develop spontaneous breathing & 53.8 & $20.7-139.6$ & $<0.001$ \\
\hline
\end{tabular}

significantly associated with neonatal deaths due to BA. This is in accordance with several previously published studies in similar settings [27] [29] [42] [48] [49]. Our findings are different from the statement that post maturity is an important risk factor of birth asphyxia [50] [51]. Furthermore, our study showed that small size at birth has protective effect whereas larger babies are at an increased risk of asphyxia related deaths. This finding is in contradiction with other studies conducted in [41] [42] [47] [52] [53]. However, this could be attributable to the fact that we did not collect data on gestational age and birth weight due to recall bias of last menstrual period LMP and non-availability of birth weight data. We used self-reported duration of pregnancy and size of baby at birth as a proxy of gestational age and birth weight. Failure to develop spontaneous breathing immediately after birth was also found to be an independent risk factor associated with increased risk of neonatal mortality due to BA [54].

Our findings reflect unsatisfactory perinatal and delivery services in the in resource-limited rural settings of Matiari, Pakistan. Such inadequacies and low quality care delivery has also been previously highlighted by other studies conducted in [55] [56]. Findings from our study highlight that early identification and intervening during the antenatal period have the potential to prevent asphyxia related neonatal mortality. Management of intrapartum complication through skilled birth attendant could help avoid adverse pregnancy and neonatal outcomes. There is an acute need to strengthen the training of local birth attendants as well as to evaluate tertiary care delivery facilities to assess their competence for management of intrapartum complications in these settings.

One of the limitations of our study is that our study was conducted on limited and specified geographic settings that involved less resourced rural setup. Larger studies are required to demonstrate the true associations in the population. Other limitations include potential reporting bias of maternal, infant symptoms and recall bias in verbal autopsy interviews. 


\section{Conclusion}

Concrete and coordinated efforts are required to decrease the burden of neonatal deaths related to BA specifically in low-resource settings. Neonatal and late fetal deaths are closely linked to maternal deaths, requiring common solutions. There is an immediate need to develop strategies for identification and management of birth asphyxia by involving all pathways to survival, including women, families, communities, community health workers, health professionals and policy makers. There is a need to maintain high coverage of skilled birth attendants, promotion of birth preparedness, essential new born care including hygiene and thermal care for new born, trained community workforce for early recognition, referrals at primary health care with well equipped and trained health personnel, training of obstetricians and paramedics staff for emergency obstetric care, and basic newborn care including preliminary resuscitation measures in low resource settings where access to health services are difficult.

\section{Acknowledgements}

This study was made possible because of the research assistants working in Matiari Yar Mohammad, Bushra Memom and data coordinators Imran Ali. Statistical assistance was provided by Dr. Salim Iqbal epidemiologist. We also thank full to assistant professor Dr. Asiha Yousfzai and senior instructor Rehana Salam for their technical support.

\section{Conflict of Interest}

All authors declare that they have no conflicts of interest.

\section{Funding Disclosure}

This study was funded by PAIMAN (Pakistan Initiative for Mothers and Newborns) and John Snow Inc., via a grant from by the US Agency for International Development (USAID).

\section{Authors' Contributions}

ZAB conceptualized the study and as principal investigator involved in all aspects of this study. SS participated in study design, data analysis and interpretation of data and reviewed final manuscript. SA critically reviewed the final manuscript. FT was project supervisor developed study protocol, data collection material and oversaw study implementation and writing of the manuscript. AR was statistician for this study and conducted data analysis. All authors reviewed and approved the final manuscript.

\section{References}

[1] UN Inter-Agency Group (2013) Levels \& Trends in Child Mortality.

[2] Lawn, J.E., et al. (2014) Every Newborn: Progress, Priorities, and Potential beyond Survival. Lancet, 384, $189-205$. http://dx.doi.org/10.1016/S0140-6736(14)60496-7

[3] (2013) Levels and Trends in Child Mortality. The World Bank, United Nations.

[4] Lawn, J.E., et al. (2012) Newborn Survival: A Multi-Country Analysis of a Decade of Change. Health Policy Plan, 27, iii6-iii28. http://dx.doi.org/10.1093/heapol/czs053

[5] Lopez, A.D., et al. (2006) Global and Regional Burden of Disease and Risk Factors, 2001: Systematic Analysis of Population Health Data. Lancet, 367, 1747-1757. http://dx.doi.org/10.1016/S0140-6736(06)68770-9

[6] (2013) Committing to Child Survival: A Promise Renewed.

[7] Lopez, A.D. and Mathers, C.D. (2006) Measuring the Global Burden of Disease and Epidemiological Transitions: 2002-2030. Annals of Tropical Medicine and Parasitology, 100, 481-499. http://dx.doi.org/10.1179/136485906X97417

[8] Leviton, A. and Nelson, K.B. (1992) Problems with Definitions and Classifications of Newborn Encephalopathy. Pediatric Neurology, 8, 85-90. http://dx.doi.org/10.1016/0887-8994(92)90026-U

[9] Casey, B.M., McIntire, D.D. and Leveno, K.J. (2001) The Continuing Value of the Apgar Score for the Assessment of Newborn Infants. New England Journal of Medicine, 344, 467-471. http://dx.doi.org/10.1056/NEJM200102153440701

[10] Murray, C.J.L. and Lopez, A.D. (1996) The Global Burden of Disease: A Comprehensive Assessment of Mortality and 
Disability Form Diseases, Injuries and Risk Factors in 1990 and Projected to 2020. Harvard University Press, Cambridge, 429-453.

[11] Lawn, J.E., Manandhar, A., Haws, R.A. and Darmstadt, G.L. (2007) Reducing One Million Child Deaths from Birth Asphyxia-A Survey of Health Systems Gaps and Priorities. Health Research Policy and Systems, 5, 4. http://dx.doi.org/10.1186/1478-4505-5-4

[12] World Health Organization (2005) World Health Report. WHO, Geneva. http://www.who.int/whr/2004/annex/en/index.html

[13] World Health Organization (1997) Basic Newborn Resuscitation: A Practical Guide. WHO, Geneva.

[14] Rademakers, R.P., van der Knaap, M.S., Verbeeten Jr., B., Barth, P.G. and Valk, J. (1995) Central Cortico-Subcortical Involvement: A Distinct Pattern of Brain Damage Caused by Perinatal and Postnatal Asphyxia in Term Infants. Journal of Computer Assisted Tomography, 19, 256-263. http://dx.doi.org/10.1097/00004728-199503000-00017

[15] Gadian, D.G., Aicardi, J., Watkins, K.E., Porter, D.A., Mishkin, M. and Vargha-Khadem, F. (2000) Developmental Amnesia Associated with Early Hypoxic-Ischaemic Injury. Brain, 123, 499-507. http://dx.doi.org/10.1093/brain/123.3.499

[16] Barkovich, A.J. (1992) MR and CT Evaluation of Profound Neonatal and Infantile Asphyxia. AJNR: American Journal of Neuroradiology, 13, 959-972.

[17] Mañeru, C., Serra-Grabulosa, J.M., Junqué, C., Salgado-Pineda, P., Bargalló, N., Olondo, M., et al. (2003) Residual Hippocampal Atrophy in Asphyxiated Term Neonates. Journal of Neuroimaging, 13, 68-74. http://dx.doi.org/10.1111/j.1552-6569.2003.tb00159.x http://dx.doi.org/10.1177/1051228402239720

[18] Toft, P.B. (1999) Prenatal and Perinatal Striatal Injury: A Hypothetical Cause of Attention-Deficit-Hyperactivity Disorder? Pediatric Neurology, 21, 602-610. http://dx.doi.org/10.1016/S0887-8994(99)00046-6

[19] Van Petten, C. (2004) Relationship between Hippocampal Volume and Memory Ability in Healthy Individuals across the Lifespan: Review and Meta-Analysis. Neuropsychologia, 42, 1394-1413. http://dx.doi.org/10.1016/j.neuropsychologia.2004.04.006

[20] de Haan, M., Wyatt, J.S., Roth, S., Vargha-Khadem, F., Gadian, D. and Mishkin, M. (2006) Brain and Cognitive-Behavioral Development after Asphyxia at Term Birth. Developmental Science, 9, 350-358. http://dx.doi.org/10.1111/j.1467-7687.2006.00499.x

[21] De Long, G.R. (1992) Autism, Amnesia, Hippocampus, and Learning. Neuroscience \& Biobehavioral Reviews, 16, 6370. http://dx.doi.org/10.1016/S0149-7634(05)80052-1

[22] Dilenge, M.E., Majnemer, A. and Shevell, M.I. (2001) Long-Term Developmental Outcome of Asphyxiated Term Neonates. Journal of Child Neurology, 16, 781-792. http://dx.doi.org/10.1177/08830738010160110201

[23] Lou, H.C. (1996) Etiology and Pathogenesis of Attention-Deficit Hyperactivity Disorder (ADHD): Significance of Prematurity and Perinatal Hypoxic-Haemodynamic Encephalopathy. Acta Paediatrica, 85, 1266-1271. http://dx.doi.org/10.1111/j.1651-2227.1996.tb13909.x

[24] Dilenge, M.E., Majnemer, A. and Shevell, M.I. (2001) Long-Term Developmental Outcome of Asphyxiated Term Neonates. Journal of Child Neurology, 16, 781-792. http://dx.doi.org/10.1177/08830738010160110201

[25] Committee on Fetus and Newborn, American Academy of Pediatrics, and Committee on Obstetric Practice, American College of Obstetricians and Gynecologists (1996) American Academy of Pediatrics: Use and Abuse of the Apgar Score. Pediatrics, 98, 141-142.

[26] Pakistan Demographic and Health Survey 2006-2007.

[27] Lee, A.C., Mullany, L.C., Tielsch, J.M., Katz, J., Khatry, S.K., LeClerq, S.C., et al. (2008) Risk Factors for Neonatal Mortality Due to Birth Asphyxia in Southern Nepal: A Prospective, Community-Based Cohort Study. Pediatrics, 121, e1381-e1390. http://dx.doi.org/10.1542/peds.2007-1966

[28] Cruz-Anguiano, V., Talavera, J.O., Vázquez, L., Antonio, A., Castellanos, A., Lezana, M.A. and Wacher, N.H. (2004) The Importance of Quality of Care in Perinatal Mortality: A Case-Control Study in Chiapas, Mexico. Archives of Medical Research, 35, 554-562. http://dx.doi.org/10.1016/j.arcmed.2004.11.014

[29] Shireen, N., Nahar, N. and Mollah, A.H. (2009) Risk Factors and Short-Term Outcome of Birth Asphyxiated Babies in Dhaka Medical College Hospital. Bangladesh Journal of Child Health, 33, 83-89.

[30] Bouwhuis, S.A. and Davis, M.D. (2004) Contribution of Sexually Transmitted Diseases and Socioeconomic Factors to Perinatal Mortality in Rural Ghana. International Journal of Dermatology, 43, 27-30. http://dx.doi.org/10.1111/j.1365-4632.2004.01841.x

[31] Gissler, M., Merilainen, J., Vuori, E. and Hemminki, E. (2003) Register Based Monitoring Shows Decreasing Socioeconomic Differences in Finnish Perinatal Health. Journal of Epidemiology and Community Health, 57, 433-439. 
http://dx.doi.org/10.1136/jech.57.6.433

[32] Stephansson, O., Dickman, P.W., Johansson, A.L. and Cnattingius, S. (2001) The Influence of Socioeconomic Status on Stillbirth Risk in Sweden. International Journal of Epidemiology, 30, 1296-1301. http://dx.doi.org/10.1093/ije/30.6.1296

[33] Surkan, P.J., Stephansson, O., Dickman, P.W. and Cnattingius, S. (2004) Previous Preterm and Small-for-GestationalAge Births and the Subsequent Risk of Stillbirth. The New England Journal of Medicine, 350, 777-785. http://dx.doi.org/10.1056/NEJMoa031587

[34] Crawford, J.S. (1966) Maternal Age as an Isolated Factor in the Incidence of Perinatal Asphyxia. American Journal of Obstetrics and Gynecology, 94, 281-282.

[35] Chalumeau, M., Salanave, B., Bouvier-Colle, M.H., de Bernis, L., Prual, A. and Bréart, G. (2000) Risk Factors for Perinatal Mortality in West Africa: A Population-Based Study of 20326 Pregnancies. MOMA Group. Acta Paediatrica, 89, 1115-1121. http://dx.doi.org/10.1111/j.1651-2227.2000.tb03361.x

[36] Jansone, M., Lindmark, G. and Langhoff-Roos, J. (2001) Perinatal Deaths and Insufficient Antenatal Care in Latvia. Acta Obstetricia et Gynecologica Scandinavica, 80, 1091-1095. http://dx.doi.org/10.1034/j.1600-0412.2001.801203.x

[37] Milsom, I., Ladfors, L., Thiringer, K., Niklasson, A., Odeback, A. and Thornberg, E. (2002) Influence of Maternal, Obstetric and Fetal Risk Factors on the Prevalence of Birth Asphyxia at Term in a Swedish Urban Population. Acta Obstetricia et Gynecologica Scandinavica, 81, 909-917. http://dx.doi.org/10.1034/j.1600-0412.2002.811003.x

[38] Treurniet, H.F., Boshuizen, H.C. and Harteloh, P.P. (2004) Avoidable Mortality in Europe (1980-1997): A Comparison of Trends. Journal of Epidemiology and Community Health, 58, 290-295. http://dx.doi.org/10.1136/jech.2002.006452

[39] Weiner, R., Ronsmans, C., Dorman, E., Jilo, H., Muhoro, A. and Shulman, C. (2003) Labor Complications Remain the Most Important Risk Factors for Perinatal Mortality in Rural Kenya. Bulletin of the World Health Organization, 81, 561-566.

[40] Hall, D.R., Smith, M. and Smith, J. (1996) Maternal Factors Contributing to Asphyxia Neonatorum. Journal of Tropical Pediatrics, 42, 192-195. http://dx.doi.org/10.1093/tropej/42.4.192

[41] Kaye, D. (2003) Antenatal and Intrapartum Risk Factors for Birth Asphyxia among Emergency Obstetric Referrals in Mulago Hospital, Kampala, Uganda. East African Medical Journal, 80, 140-143.

[42] Wu, Y.W., Backstrand, K.H., Zhao, S., Fullerton, H.J. and Johnston, S.C. (2004) Declining Diagnosis of Birth Asphyxia in California: 1991-2000. Pediatrics, 114, 1584-1590. http://dx.doi.org/10.1542/peds.2004-0708

[43] Demirci, O., Tuğrul, A.S., Turgut, A., Ceylan, S. and Eren, S. (2012) Pregnancy Outcomes by Mode of Delivery among Breech Births. Archives of Gynecology and Obstetrics, 285, 297-303. http://dx.doi.org/10.1007/s00404-011-1956-0

[44] Khatoon, S.A., Kawser, C.A. and Talukder, M.Q.K. (1989) Clinical Spectrum and Outcome of Birth Asphyxiated Babies in Neonatal Unit of IPGMR: A Study of 122 Cases. Bangladesh Journal of Child Health, 13, 7-15.

[45] Daga, A.S., Daga, S.R. and Patole, S.K. (1990) Risk Assessment in Birth Asphyxia. Journal of Tropical Pediatrics, 36, 34-39. http://dx.doi.org/10.1093/tropej/36.1.34

[46] Chandra, S., Ramji, S. and Thirupuram, S. (1997) Perinatal Asphyxia: Multivariate Analysis of Risk Factors in Hospital Births. Indian Pediatrics, 34, 206-212.

[47] Paul, V.K., Singh, M., Sundaram, K.R. and Deorari, A.K. (1997) Correlates of Mortality among Hospital-Born Neonates with Birth Asphyxia. The National Medical Journal of India, 10, 54-57.

[48] Goldberg, R.N., Cabal, L.A., Sinatra, F.R., Plajstek, C.E. and Hodgman, J.E. (1979) Hyperammonemia Associated with Perinatal Asphyxia. Pediatrics, 64, 336-341.

[49] Sampa, R.P., Hossain, Q.Z. and Sultana, S. (2013) Observation of Birth Asphyxia and Its Impact on Neonatal Mortality in Khulna Urban Slum Bangladesh. International Journal of Advanced Nutritional and Health Science, 1, 1-8.

[50] Azam, M., Khan, P.A. and Malik, F.A. (2004) Birth Asphyxia: Risk Factors. The Professional, 11, 416-423.

[51] Gomella, T.L., et al. (1999) Perinatal Asphyxia. The Professional, 480-489.

[52] Kobayashi, K., Ibara, S., Kusumoto, M., Maruyama, H., Kato, E., Khreisat, W. and Ha-Bahbeh, Z. (2005) Risk Factors of Birth Asphyxia: A Study at Prince Ali Ben Al-Hussein Hospital, Jordan. Pakistan Journal of Medical Sciences, 21, 30-32.

[53] Al, A. (1991) Birth Asphyxia and HIE, Incidence and Severity. Annals of Tropical Paediatrics, 11, $331-335$.

[54] Ersdal, H.L., Mduma, E., Svensen, E. and Perlman, J. (2012) Birth Asphyxia: A Major Cause of Early Neonatal Mortality in a Tanzanian Rural Hospital. Pediatrics, 129, e1238-e1243. http://dx.doi.org/10.1542/peds.2011-3134

[55] Bhutta, Z.A. (1994) The Plight of Newborn Care in Pakistan. Economic Review, 25, 9. 
[56] Tariq, P. and Kundi, Z. (1999) Determinants of Neonatal Mortality. Journal of Pakistan Medical Association, 49, 5660.

[57] Lee, A.C. (2007) Risk Factors for Birth Asphyxia Mortality in a Community-Based Setting in Southern Nepal. Johns Hopkins School of Public Health.

[58] Baskett, T.F., Allen, V.M., O’Connell, C.M. and Allen, A.C. (2006) Predictors of Respiratory Depression at Birth in the Term Infant. BJOG: An International Journal of Obstetrics \& Gynaecology, 113, 769-774. http://dx.doi.org/10.1111/j.1471-0528.2006.00987.x

[59] Buchmann, E.J., Pattinson, R.C. and Nyathikazi, N. (2002) Intrapartum-Related Birth Asphyxia in South AfricaLessons from the First National Perinatal Care Survey. South African Medical Journal, 92, 897-901.

[60] Mbweza, E. (2000) Risk Factors for Perinatal Asphyxia at Queen Elizabeth Central Hospital, Malawi. Clinical Excellence for Nurse Practitioners, 4, 158-162. 
Scientific Research Publishing (SCIRP) is one of the largest Open Access journal publishers. It is currently publishing more than 200 open access, online, peer-reviewed journals covering a wide range of academic disciplines. SCIRP serves the worldwide academic communities and contributes to the progress and application of science with its publication.

Other selected journals from SCIRP are listed as below. Submit your manuscript to us via either submit@scirp.org or Online Submission Portal.
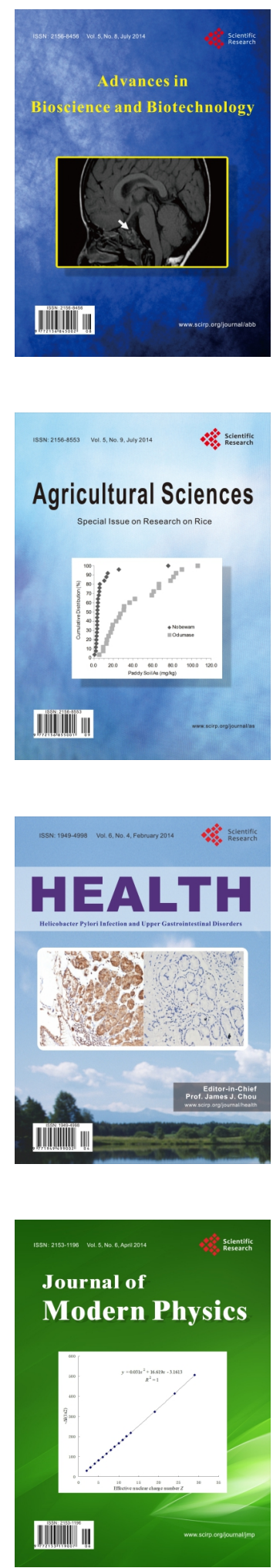
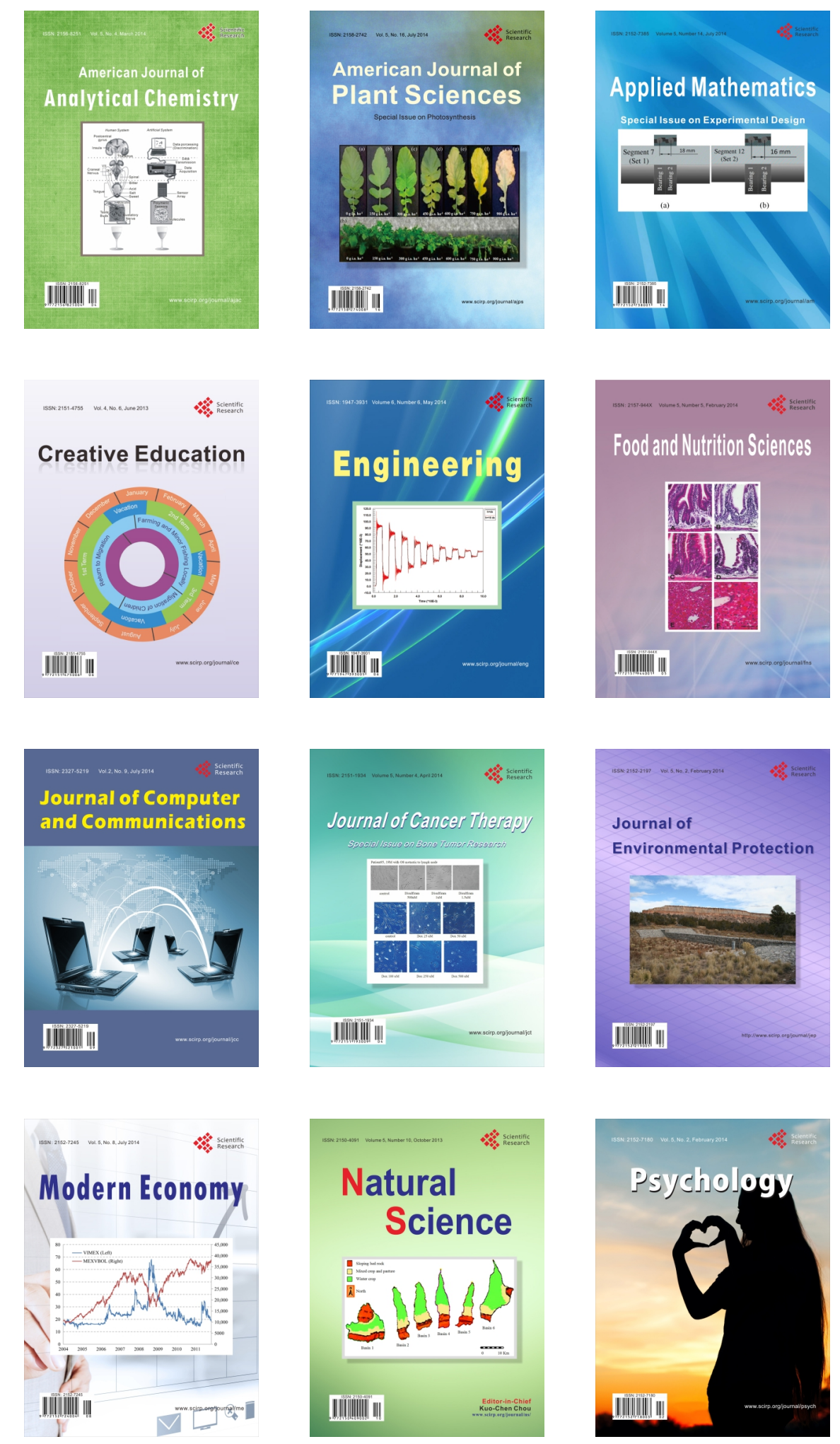